\title{
Features of Alloyed a Matry of Water-Dispersed Iron Powders
}

\author{
Ivanka Miteva \\ Faculty of Mechanical and Precision \\ Engineering \\ Technical University of Gabrovo \\ Gabrovo, Bulgaria \\ idmiteva_prestij@abv.bg
}

\author{
Ivan Vinev \\ Faculty of Mechanical and Precision \\ Engineering \\ Technical University of Gabrovo \\ Gabrovo, Bulgaria \\ ivinev@abv.bg
}

\author{
Ivan Mitev \\ Faculty of Economics \\ Technical University of Gabrovo \\ Gabrovo, Bulgaria \\ imitev@tugab.bg
}

\begin{abstract}
The publication examines the peculiarities of alloying a matrix of water-dispersed iron powders of the type ASC 100.29, AHC 100.29 and ABC 100.30. The possible ways of alloying in powder metallurgy are presented. The influence of the main alloying elements - copper, nickel, phosphorus, molybdenum, etc. was traced. on the technological process in the production of powder metallurgical details. A special place is given to the alloying elements intensifying the process of coagulation of the pores in the matrix during sintering - copper and phosphorus. Graphical dependences for the influence of copper on the dimensional changes of the iron matrix at different sintering temperatures are presented.
\end{abstract}

Keywords - copper, nickel, phosphorus, powder metallurgy, water-dispersed iron powders.

\section{INTRODUCTION}

General purpose sintered structural materials from iron powders and alloyed iron matrices represent a major part of powder metallurgical production. In developed industrial countries, the relative share of these parts for the needs of automotive, machine and instrument making, electronics, as well as in a number of other areas of the metalworking industry is significant $[8,14,15,16,17,19]$. With the correct selection of the initial composition of the charge in many cases the parts obtained by the method of powder metallurgy have similar operational properties with those of the parts obtained by conventional technologies (by casting) [7]. The main advantage of the products obtained by the method of powder metallurgy is the absence or insignificant mechanical processing without loss of the material in the form of shavings, high degree of preservation of the dimensions and quality of the surfaces, accuracy of the mass, etc.[9,11].
Structural products in powder metallurgy, similar to those in conventional ones, are usually made of alloys. Pure metals are used only if the products require special physical properties. Obtaining certain physical and mechanical properties requires the use of alloyed iron powders. Many of the alloying elements used in ferrous metallurgy to improve the properties of iron are used by analogy in powder metallurgy. However, there are some significant features [7,9,17]:

* the application of some alloying elements widely used in ferrous metallurgy - chromium, manganese, silicon, titanium and vanadium - is difficult due to their strong affinity for oxygen;

* the surface layer of the corresponding oxide, which is formed during oxidation, is very difficult to reduce under normal sintering conditions, moreover, as a result of reactions with the sintering medium and the oxygen present in the iron powder, additional oxidation often takes place during the sintering process, due to which diffusion is difficult and a material with low physicomechanical properties is obtained, therefore the oxides of the alloying additives, which are mixed with the iron powder, must be reduced more easily during sintering than the oxides of the iron itself;

\& in powder metallurgy some elements that are used to a limited extent in ferrous metallurgy - copper and phosphorus - are widely used for alloying;

\& in powder metallurgy some elements that are used to a limited extent in ferrous metallurgy - copper and phosphorus - are widely used for alloying; 
\& comparison with classical metallurgy larger quantities of alloying additives are needed here in order to obtain the desired properties;

\# important factor in selecting the type and quantity of the alloying element is its influence on the accuracy of the dimensions of the sintered products.

For these reasons, the chemical composition of a large proportion of sintered steels differs significantly from the composition of ordinary steels with the same field of application.

In the present publication the aim is to study the peculiarities of alloying an iron matrix based on waterdispersed iron powders with copper, nickel and other alloying elements.

\section{MATERIALS AND METODS}

Samples based on water-dispersed iron powders type ASC 100.29, AHC 100.29 and ABC 100.30 were used in the research process. The iron matrix is alloyed with copper, nickel, phosphorus and carbon.

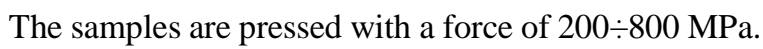
The measured density after sintering varies in the range of $6.00 \div 7.00 \mathrm{~g} / \mathrm{cm}^{3}$.

The determination of the mechanical characteristics of the tested samples is done according to the standardized methods for determining the tensile strength, the relative elongation and the change in the linear dimensions [12]

An increase in the size of the parameter of the crystal lattice of iron during its alloying with copper was determined by the method of X-ray diffraction analysis [13].

\section{RESULTS AND DISCUSSION}

The final complex of physical and mechanical properties of the sintered materials largely depends on the way of introducing the alloying elements in them. In powder metallurgy, several methods of alloying are used: mechanical mixtures; alloy powders, partially alloyed powders - Fig.1 [19].

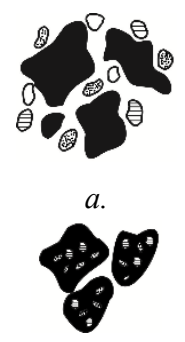

b.

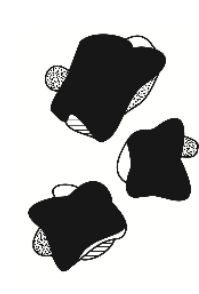

C.
Fig. 1. Alloying schemes in powder metallurgy: a - mechanical mixture; $b$ - alloyed powder; c - partially alloyed powder.

From Fig. 1, it can be seen that the most suitable for use in production seems to be the finished alloyed powder, because the individual powders particles have the same composition as the final product. Such powders are obtained by sputtering, mechanical grinding and coreduction. The method of pulverization of metal melts has found the widest industrial application [1,6,17]. In this way, alloys of many non-ferrous metals are obtained bronze, brass, aluminium alloys, as well as low- and highalloy steels.

The use of alloyed powders makes it possible to maximize the use of alloying elements, to obtain alloys with high homogeneity of structure, and hence with the greatest uniformity of properties and accuracy of the geometric parameters of the products. Due to their higher hardness, however, alloy powders have a relatively poor compaction, which is of great importance when pressing parts with a more complex configuration. In such cases, high-energy molding methods are suitable - hot dynamic pressing, high-speed pressing, etc. [6,11].

Until now, the compression of mechanical mixtures of the necessary components has been more widely used in powder metallurgy, as the desired alloys are formed by diffusion during sintering $[6,17]$.

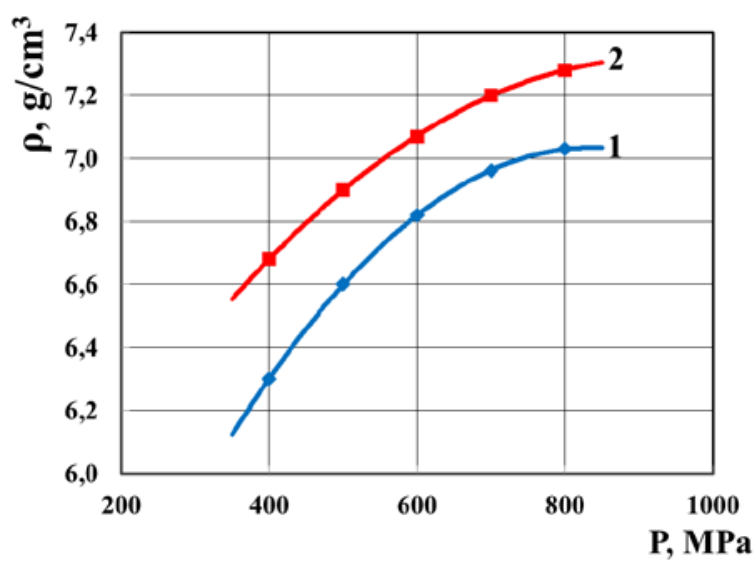

Fig.2.Compactness of alloyed powders- 1 and mechanical mixtures -2

with composition $\mathrm{Fe}+2 \% \mathrm{Ni}+0.5 \% \mathrm{Mo}+0.5 \% \mathrm{C}$

Figure 2 shows experimental results proving a much better compaction of a mechanical mixture compared to an alloyed powder with the same composition.

The use of mechanical mixtures requires much better mixing of the components before pressing, higher temperature and longer duration of the sintering process in order to homogenize the alloy. In some cases, in order to obtain materials with special properties - for example, with high wear resistance, the creation of nonequilibrium structures is resorted to.

A compromise between alloy powders and mechanical mixtures is pre-alloyed powders. During sintering, the alloying elements diffuse relatively quickly into the base metal, which allows the process to be carried out under more favourable technological conditions. The heat treatment is carefully controlled so that the interaction 
between the alloying elements and the iron powder is in the initial stage.

The alloying of iron with copper or with copper in combination with other elements makes it possible to obtain alloys with very good physical and mechanical properties [3,10,17]. Iron-copper alloys are usually obtained from mechanical mixtures. A specific method of alloying in this case is the impregnation of a porous iron skeleton with molten copper or its alloys. Copper is also used in the preparation of pre-diffusion-doped powders and much less frequently in ready-made alloy powders.

The formation of the structure of the alloy during sintering of a mechanical mixture of iron and copper powder is of both theoretical and practical interest. The iron-copper system has a limited solubility of the components in the solid state - at a temperature of $1094^{\circ} \mathrm{C}$ iron dissolves about $8 \% \mathrm{Cu}$, and copper in turn can dissolve about $4 \% \mathrm{Fe}$ [10]. As the temperature decreases, the mutual solubility decreases. Eutectoid decay occurs at $850^{\circ} \mathrm{C}$ and a mixture of $\alpha$ - and $\varepsilon$-mixed crystals is observed at room temperature. In a solid solution with iron remains less than $0.15 \%$ copper, and above this amount of copper in the structure is in free form. The size and shape of the copper inclusions depend on: the cooling rate; the total amount of copper; temperature and duration of sintering.

The most commonly used powder materials based on water-dispersed iron powders of the type ASC 100.29, AHC 100.29 and ABC 100.30 are alloyed with $1 \div 10 \%$ copper. Unlike conventional metallurgy in powder metallurgy, copper is the main alloying element, and its advantages are as follows [2,7]:

\# good mixing with iron powder;

* easy reducibility of copper oxides;

* formation of a liquid phase during sintering at relatively low temperatures.

This is the most pronounced difference in the goals set for alloying in conventional technologies and in powder metallurgy.

Together with the increase of the strength characteristics during sintering, the copper helps to increase the parameters of the crystal lattice of the iron depending on the copper diffused in it - fig.3. This helps to compensate for the shrinkage of the iron matrix during sintering.

Our experiments show that when alloying an iron matrix of water-dispersed iron powders ABC 100.29 with 2.0\% copper after a single double-sided pressing and sintering at $1000 \div 1200^{\circ} \mathrm{C}$ for $1 \mathrm{~h}$, practically no changes in the linear dimensions of the parts are registered. - fig. 4.

The figure shows that an increase in the copper concentration in the iron matrix leads to an increase in the volume of sintered parts, as this increase is most significant at a concentration of copper in the iron briquette $-8 \div 10 \%$.

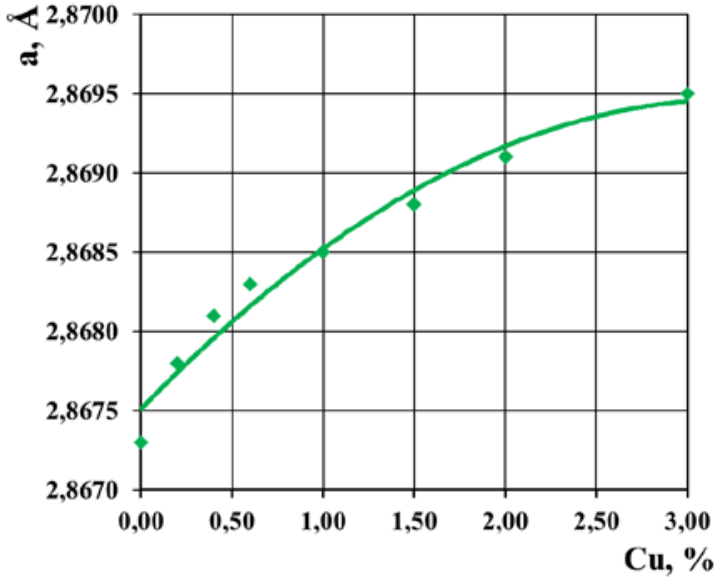

Fig. 3. Changing the parameter of the crystal lattice of iron during alloying with copper

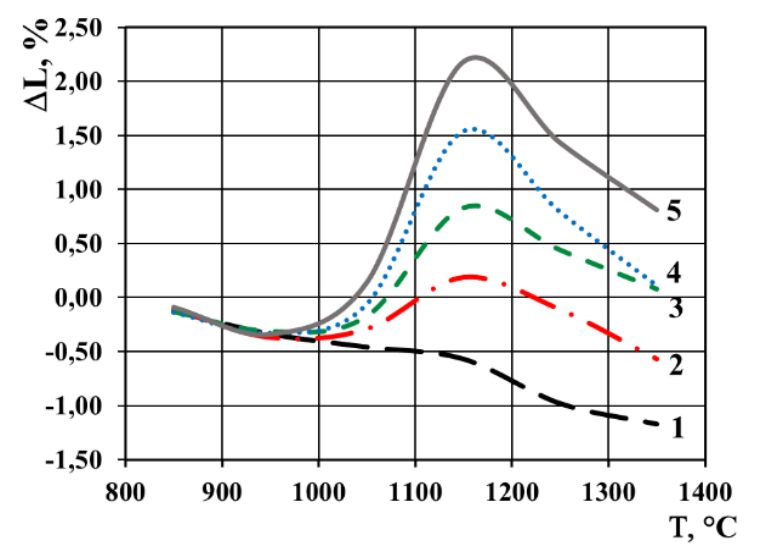

Fig. 4. Dimensional changes depending of an iron matrix of $\mathrm{ABC} 100.29$ alloyed with copper: 1 - 0\% Cu; 2 - 2\% Cu; 3 - 4\% Cu; $4-6 \% \mathrm{Cu} ; 5-8 \% \mathrm{Cu}$.

The addition of other alloying elements can affect the process in one direction or another. It was found that the addition of carbon to the iron-copper system leads to a reduction in the size of the workpiece. The same is found when adding nickel and tungsten. These limit the solubility of copper in iron and thus reduce the increase in the volume of the parts. Therefore, in combination with the alloying elements, powder metallurgical alloys with increased strength can be realized while satisfactorily preserving the size of the workpieces.

Highly alloyed with copper - up to $20 \%$, powder steels can be obtained by infiltration of pre-sintered carcasses or water-dispersed iron powder pre-alloyed with copper. As the iron frames can be pressed to the required dimensions, high-precision powder products are obtained by infiltration. From the experimental results of Fig.5. it is seen that the sintered steels double their strength after infiltration with copper. 


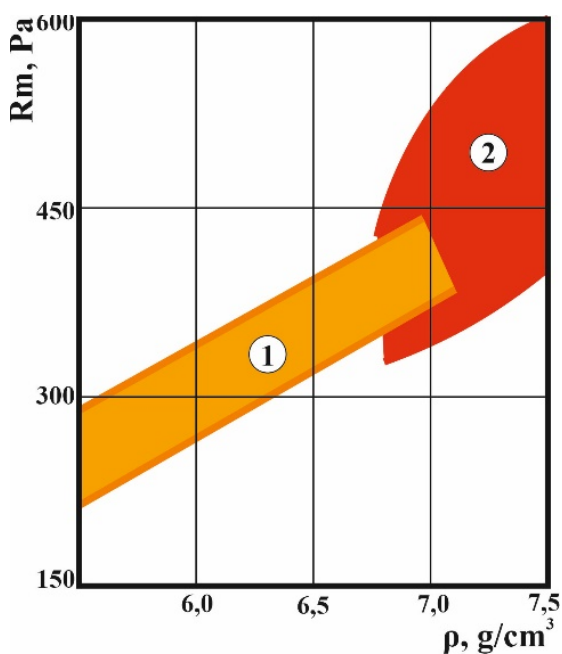

Fig.5. Tensile strength of iron matrix based on powders ASC 100.29, ABC100.29 and AHC 100.30 after alloyed with $2 \% \mathrm{Cu}-1$ and infiltration with $20 \% \mathrm{Cu}-2$.

The measured tensile strength after diffusion annealing and disperse hardening of powder materials based on iron powders ABC 100.29, containing $1.0 \%$ carbon and $15 \%$ copper depending on their density reaches $1150 \div 1250$ $\mathrm{MPa}$, at relatively high values of relative elongation $-4 \div$ $6 \%$.

In powder metallurgy after copper, the next most common alloying element is nickel. Like copper, it has a weak affinity for oxygen. Its introduction makes it possible to obtain appropriate values for strength and ductility. The Fe-Ni system refers to the case of unlimited solubility of solid components [1,7]. Iron and nickel form a continuous series of solid solutions without brittle compounds. Unlike the $\mathrm{Fe}-\mathrm{Cu}$ system, here the partial diffusion coefficients differ insignificantly and the effect of volume increase is almost imperceptible. Nickel has a high activating ability during sintering, which manifests itself at relatively high temperatures - above $1150^{\circ} \mathrm{C}$, and a longer process duration. Alloying iron with nickel slows down the growth of crystals during sintering, which helps to increase shrinkage during the final stages of the process.

In the conducted experiments it was found that the way of doping has a great influence on the structure of Fe-Ni products. When working with finished alloy powders after firing, the structure remains homogeneous, single-phase and is externally similar to the structure of non-alloy iron powder products. When using mechanical mixtures of iron and nickel powder, the final structure depends exclusively on the firing mode. At temperatures up to $850^{\circ} \mathrm{C}$, regardless of the duration of sintering, there is practically no interaction between the nickel and iron particles in the matrix.

As the temperature rises, nickel dissolves in iron. The alloys obtained under such conditions are characterized by a spotted, inhomogeneous structure. Only when the temperature rises to $1250^{\circ} \mathrm{C}$ and the sintering duration exceeds $120 \mathrm{~min}$ does the alloy acquire a single-phase structure.
From the experimental results obtained in the study of iron-nickel samples, it was found that the properties of copper-alloyed steel steels can be significantly improved by adding nickel powders to the charge. The measured values for the tensile strength of samples doped with $3 \%$ copper and $2.5 \%$ nickel vary in the range of $450 \div 550$ $\mathrm{MPa}$, and when the concentration of nickel increases to $5 \%$, the values for the tensile strength increase by approximately $100 \mathrm{MPa}$. When optimizing the concentration of copper and nickel in the briquette of iron powder ABC 100.29 (4.5\% copper and 5\% nickel) the measured values for tensile strength reach $750 \mathrm{MPa}$. But at the expense of significantly reducing the values for elongation. If for iron-nickel steels with $5 \% \mathrm{Ni}$ the measured elongation is of the order of $14 \div 16 \%$, then for the considered triple system it is only $4 \%$.

We managed to increase the tensile strength values found in the experiments by adding $0.5 \% \mathrm{C}$ to the ternary system, but at the expense of the results for the relative elongation. The measured mechanical characteristics of powder samples based on ABC 100.29 iron powders alloyed with $7 \% \mathrm{Ni}, 2.0 \% \mathrm{Cu}$ and $0.5 \% \mathrm{C}$ at a briquette density of $7.01 \mathrm{~g} / \mathrm{cm} 3$ are - tensile strength $635 \mathrm{MPa}$, elongation $2.5 \div 3 \%$ and hardness HRB 87. After heat treatment (hardening of $950^{\circ} \mathrm{C}$ in oil), the tensile strength increases to $1055 \mathrm{MPa}$, the hardness HRC47, but the relative elongation is only $1 \div 2 \%$.

The main representative of the alloying elements from the group of non-metals in powder metallurgy is phosphorus [4,5]. In ferrous metallurgy it is considered an undesirable impurity, as in steels it increases the tendency to liquation and favours the formation of brittle phosphides. For strength reasons, the concentration of phosphorus in powder steels is limited to $0.3 \div 0.6 \%$.

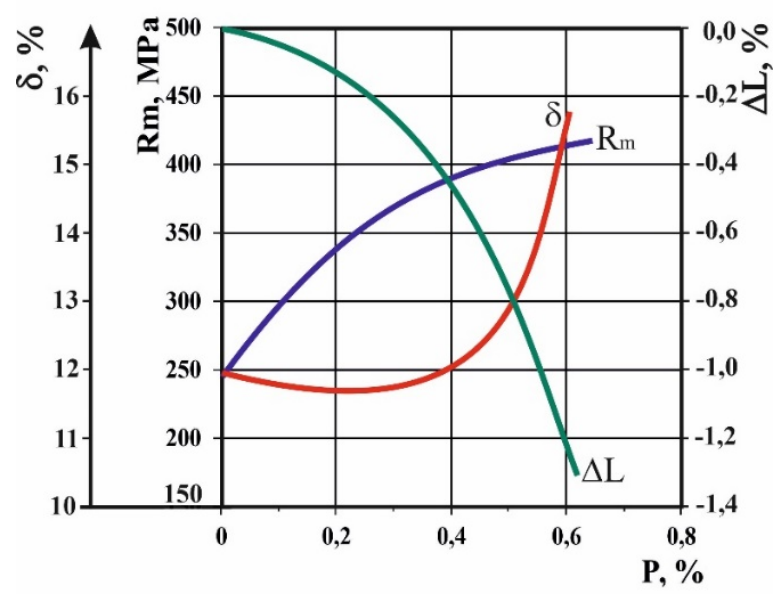

Fig.6. Dependence of tensile strength - Rm, elongation - $\delta$ and change of linear dimensions $-\Delta \mathrm{L}$, on the concentration of phosphorus in the iron matrix

As a result of the formation of a solid solution of iron with phosphorus, the ferrite component in the tested samples is stabilized. The tensile strength of samples of iron powder ASC100.29 and ABC 100.30 alloyed with $0.5 \%$ phosphorus is in the range of $400 \div 450 \mathrm{MPa}$ - Fig. 6 , but thanks to the stabilized ferrite phase the plasticity of the 
parts is very high and the relative elongation of the parts reaches $-14 \div 16 \%$ - Fig. 6 .

As a result of the formation of solid solutions with iron, phosphorus stabilizes Fe a. The iron-phosphorus state diagram shows that in the case of alloys with a phosphorus concentration $\geqslant 0.55 \%$, the sintering process practically proceeds without phase transformations. The increased rate of self-diffusion in the $\alpha$ - phase favours the migration of atoms during sintering, which allows the process to be realized at temperatures of the order of $1000^{\circ} \mathrm{C}$. In the case of an iron matrix doped with $0.3 \%$ phosphorus, the achieved hardening of the solid solution of phosphorus in the iron reaches values similar to those in the case of alloying the iron matrix with $2 \%$ copper. However, it should be borne in mind that the measured relative shrinkage of the parts at a phosphorus concentration $\geqslant$ $0.4 \%$ may exceed $1 \%$ - fig. 6 . Therefore, alloying the iron matrix with phosphorus is not recommended for the manufacture of products with increased dimensional accuracy requirements.

In order to increase the strength characteristics of the studied iron matrices in the presence of phosphorus in them and to preserve the linear dimensions of the products, tests were also performed on samples with the addition of copper or nickel.

In the triple systems Fe-Cu-P and Fe-Ni-P at sintering temperatures above $950^{\circ} \mathrm{C}$ the process takes place in the presence of a liquid phase which accelerates the process of sintering and coagulation of the pores. Under certain conditions, in particular in the case of the Fe-Ni-P ternary system, as a result of solid solutions formed in the initial stage of sintering, instead of shrinking the blanks, their size increases, which can be used as a compensating mechanism of shrinkage.

\section{CONCLUSIONS}

The following more important conclusions can be formulated from the conducted research and the results obtained:

\# Powder metallurgy is a technological process that allows the production of unique materials that are impossible to obtain by applying conventional metallurgical technologies. The mechanical mixing in solid state of the components allows the use of copper and phosphorus as alloying elements, which in practice do not find application in conventional metallurgical technologies.

\# The alloying of the ferrous matrix in powder metallurgy can be realized in three ways - by mechanical mixtures, partially and completely alloyed powders. It has been proven that with the same pressing forces the compaction of the mechanical mixtures is $0.30 \mathrm{~g} / \mathrm{cm}^{3}$ higher than the pre-alloyed powders.

\# The alloying of iron matrices from waterdispersed powders with copper and phosphorus allows the sintering process to be realized in the presence of a liquid phase. This favours the coagulation of the pores, leads to compaction of the blanks and increase their mechanical properties.

* Alloying iron with nickel slows down the growth of crystals during sintering, which helps to increase shrinkage during the final stages of the process.

\section{REFERENCES}

[1] N. Manukyan, Technology Powder Metallurgy. Yerevan, Aystan, 1986, p.232

[2] I.May, L. Schetky, Cooper in iron and steel, John Wiley and sons Toronto, 1988, p.307, ISBN 0-471-05913-7

[3] I. Mitev, Tensile strength after sintering and aging iron-copper cermet. Yearbook of TU-Varna, 2001, p.104 $\div 110$.

[4] I. Mitev, I. Vinev, Properties of Iron Powder Materials Alloyed with $0.45 \%$ Phosphorus, Machine Building and Machine Science, Vol. 9, 2009, p.61 $\div 64$, ISSN 1312-8612.

[5] I. Mitev, I.Vinev, Sintering Powder Metallurgy Materials from Iron-phosphorus System, International Conference "Unitech, 10", Gabrovo, 2010, Volume II, s.178 $\div$ 184, ISSN 1313-230X

[6] Mitev, I., Powder Metallurgy - part I (Receive powder metallurgy materials and products, University Press „V. Aprilov", Gabrovo, 2004, ISBN 954-4683-233-2

[7] I. Mitev, Powder Metallurgy - part II (Powder Metallurgical Products with Sructural and Instrumental Purpose, University Press „V. Aprilov", Gabrovo, 2004, ISBN 954-4683-234-0.

3] I. Mitev, Contemporary industrial technologies - part III / Progressive methods for mechanical forming /, EX-PRESS, Gabrovo, 2016, ISBN 978-954-490-511-8

[9] I. Mitev, Modern Industrial Technology - part III, (Progressive methods of mechanical shaping), EX-PRESS, Gabrovo, 20016, ISBN 978-954-490-511-8

[10] I. Mitev, Copper in two-component powder metallurgical systems, EX-PRESS, Gabrovo, 2019, ISBN 978-954-490632-0

[11] I. Mitev, Technologies for chipless forming, EX-PRESS, Gabrovo, 2021, ISBN 978-954-490-492-6

[12] I. Mitev, Structural Analysis,, EX-PRESS, Gabrovo, 2013, ISBN 978-954-490-363-3

[13] I. Mitev, Crystallography, EX-PRESS, Gabrovo, 2012, ISBN 978-954-490-3610-7

[14] N. Nikolova, Intellectual Capital Management used for Optimizing the Activities of Modern Small and Medium Enterprises / Companies, 4th International Conference "Economics and Management-Based on New Technologies", EMoNT 2014, 12-15 June 2014, Vrnjačka Banja, Serbia., pp.258-262, ISBN 978-86-6075-045-9

[15] N. Nikolova, Entrepreneurial "BLUE" Practices for Sustainable Development and Resources Efficiency, 12th International Scientific and Practical Conference “ENVIRONMENT. TECHNOLOGY. RESOURCES.”, June 20-22, 2019, Rezekne Academy of Technologies, Rezekne, Latvia, Volume I, 198-203, ISSN 1691-5402, ISSN 2256070X

[16] D. Petrova, Intelligent, Innovative and Sustainable Industryin Bulgaria - Prospekts and Challenges, Environment. Technology. Recourses - Proceeding of the 12th International Scientific and Practical Conference, Rezekne Academy of Technologies, Rezekne, Latvia, 2019, ISSN 1691-5402, p.210-215.

[17] R. Todorov and other, Materials and Equipment for Powder Metallurgical Construction Products, Publishing BAS, Sofia, 1988 
Ivanka Miteva, et al. Features of Alloyed a Matryx of Water-Dispersed Iron Powders

[18] P. Tomchev, N. Nenov, R. Ivanova, Instantaneous water heater with induction heater operating with grid frequency, „Research and Development in Mechanical Industry“ RaDMI 2012, 13-17 September 2012, Vrnjačka Banja, Serbia, SaTCIP Ltd., Technical-Mechanical School in Trstenik, ISBN 978-86-6075-036-7, Volume II, pp.1214-1218.
[19] I.Vinev, Peculiarities of iron matrix alloying in powder metallurgy, MNK UNITECH ${ }^{18}$, Gabrovo, volume II, p.239 $\div$ 244, 2018, ISSN 1313-230X 